\title{
mRNA Treatment Rescues Niemann-Pick Disease Type C1 in Patient Fibroblasts
}

\author{
Denzil Furtado, ${ }^{1}$ Christina Cortez-Jugo, ${ }^{1}$ Ya Hui Hung, ${ }^{2}$ Ashley I. Bush, ${ }^{3}$ and Frank Caruso ${ }^{1 *}$ \\ ${ }^{1}$ Department of Chemical Engineering, The University of Melbourne, Parkville, Victoria 3010, \\ Australia \\ ${ }^{2}$ The Florey Institute of Neuroscience and Mental Health, Parkville, Victoria 3052, Australia \\ ${ }^{3}$ Melbourne Dementia Research Centre, The Florey Institute of Neuroscience and Mental Health, The \\ University of Melbourne, Parkville, Victoria 3052, Australia
}

*Email: fcaruso@unimelb.edu.au

\begin{abstract}
Messenger RNA (mRNA) holds great potential as a disease-modifying treatment for a wide array of monogenic disorders. Niemann-Pick disease type C1 (NP-C1) is an ultra-rare monogenic disease that arises due to loss-of-function mutations in the NPC1 gene, resulting in the entrapment of unesterified cholesterol in the lysosomes of affected cells and a subsequent reduction in their capacity for cholesterol esterification. This causes severe damage to various organs including the brain, liver, and spleen. In this work, we describe the use of NPC1-encoded mRNA to rescue the protein insufficiency and pathogenic phenotype caused by biallelic NPC1 mutations in cultured fibroblasts derived from an NP-C1 patient. We first evaluated engineering strategies for the generation of potent mRNAs capable of eliciting high protein expression across multiple cell types. We observed that "GC3" codon optimization, coupled with N1-methylpseudouridine base modification, yielded an mRNA that was approximately a thousand-fold more potent than wildtype, unmodified mRNA in a luciferase reporter assay, and consistently superior to other mRNA variants. Our data suggest that the improved expression associated with this design strategy was due in large part to the increased secondary structure of the designed mRNAs. Both codon optimization and base modification appear to contribute to increased secondary structure. Applying these principles to the engineering of NPC1-encoded mRNA, we observed a normalization in NPC1 protein levels after mRNA treatment, as well as a rescue of the mutant phenotype. Specifically, mRNA treatment restored the cholesterol esterification capacity of patient cells to wildtype levels, and induced a significant reduction in both unesterified cholesterol levels ( $>57 \%$ reduction compared to Lipofectamine-treated control in a cholesterol esterification assay) and lysosome size (157 $\mu \mathrm{m}^{2}$ reduction compared to lipofectamine-treated control). These findings show that engineered mRNA can correct the deficit caused by NPC1 mutations. More broadly, they also serve to further validate the potential of this technology to correct diseases associated with loss-of-function mutations in genes coding for large, complex, intracellular proteins.
\end{abstract}

\section{Introduction}

Niemann-Pick disease type $\mathrm{C}(\mathrm{NP}-\mathrm{C})$ is a rare inherited neurovisceral disorder that arises due to inactivating mutations in one of two protein-coding genes, NPC1 (95\% of cases) or NPC2. ${ }^{1}$ The incidence of NP-C1 disease is approximately $1 / 90,000$ live births, but due to the extreme heterogeneity of clinical phenotypes, a late-onset form of NP-C1 is estimated to have a much higher incidence rate of between 1/19,000-1/36,000. ${ }^{2}$ Both NPC1 and NPC2 are endo-lysosomal proteins that, under normal circumstances, act cooperatively to shuttle unesterified cholesterol obtained from endocytosed lipoproteins across the late endosomal membrane into the cytosol. ${ }^{3} \mathrm{NPC} 2$, a small, soluble protein, binds unesterified cholesterol in the lumen and presents it to the $\mathrm{N}$-terminal domain of NPC1 ${ }^{4,5}$ NPC1, which by contrast is a large, multipass transmembrane protein, subsequently facilitates cholesterol egress across the endosomal membrane., ${ }^{4,6}$ 
In NP-C disease, however, defective trafficking leads to the sequestration and accumulation of unesterified cholesterol and glycosphingolipids in lysosomes of cells throughout the body. This results in damage to various organs including the central nervous system (CNS), liver, spleen, and sometimes the lungs. ${ }^{1}$ The clinical manifestations of these pathologies often arise at different times and follow very different trajectories. ${ }^{7}$ In contrast, some severe infantile forms of the disease result in fatal liver or respiratory failure, ${ }^{7}$ while other adult forms result in late-onset neurodegenerative disease. ${ }^{2}$ Nevertheless, classical neurological manifestations in the majority of patients include vertical supranuclear gaze palsy, cerebellar ataxia, dystonia, dysarthria, and dysphagia, gelastic cataplexy, and epileptic seizures. ${ }^{1,2,7}$ The severity of these symptoms tends to worsen with time, since NP-C disease is chronic, progressive, and invariably fatal. ${ }^{8}$

Despite many and varied efforts, few treatments for NP-C disease exist. ${ }^{9}$ No drug has yet been approved by the United States (US) Food and Drug Administration (FDA), although various compounds have been introduced into late-stage clinical trials, including arimoclomol, an inducer of heat shock proteins (ClinicalTrials.gov identifier NCT02612129); ${ }^{10}$ miglustat, a glucosylceramide synthase inhibitor (ClinicalTrials.gov identifier NCT01760564); ${ }^{11,12}$ and hydroxypropyl-betacyclodextrin, a cyclic oligosaccharide that has been shown to sequester and transport unesterified cholesterol from the late endosome to the cytosol, thereby enabling increased cholesterol esterification (ClinicalTrials.gov identifier NCT04860960)..$^{13}$ Miglustat is currently approved in the EU, Canada and Japan for the treatment of progressive neurological complications in NP-C disease, and is frequently prescribed off-label for NP-C1 disease in the US. ${ }^{12}$ Hydroxypropyl-beta-cyclodextrin, meanwhile, has been approved under compassionate use protocols to treat several NP-C disease patients worldwide since 2009. ${ }^{14}$ Even with the aforementioned drugs, however, the prognosis for patients remains poor and the disease burden remains high.

Since NP-C disease occurs due to a lack of properly functioning NPC1 or NPC2 protein, therapeutic approaches that introduce a functional copy of the affected protein have been explored. Protein replacement therapy is not available for NP-C1 disease since it involves a transmembrane protein, but has demonstrated partial efficacy in a mouse model of NP-C2 disease. ${ }^{15}$ Viral gene therapy strategies, reliant on adeno-associated viral vector serotype 9 (AAV9), have shown promise in mouse models of NP-C1 disease when administered systemically ${ }^{16}$ and locally. ${ }^{17,18}$ However, AAV gene therapy has also been associated with some important drawbacks, including the risk of insertional mutagenesis, potentially-fatal liver toxicity, and strong immunogenicity resulting in an inability to redose. $^{19,20}$

Messenger RNA (mRNA)-based drugs are an emerging class of therapeutics that have the potential to restore wildtype protein levels and function in the context of inherited diseases, without the genotoxicity concerns associated with viral DNA delivery. ${ }^{21-23}$ Since mRNA therapy involves supplying cells with a single-stranded mRNA template and relying upon the ribosomal machinery to produce fully functional bioactive proteins in situ, it enables the replacement of large, complex proteins such as transmembrane proteins. ${ }^{24}$ Preclinical studies have demonstrated the efficacy of mRNA-based therapeutics across a host of different genetic diseases, including cystic fibrosis, ${ }^{24}$ alpha 1-antitrypsin deficiency, ${ }^{25}$ methylmalonic acidemia, ${ }^{26}$ and hemophilia $\mathrm{B},{ }^{27}$ among others. Clinical trials are ongoing to investigate the efficacy of mRNA for the treatment of propionic acidemia (ClinicalTrials.gov Identifier: NCT04159103) and cystic fibrosis (ClinicalTrials.gov Identifier: NCT03375047).

Structurally, an in vitro transcribed (IVT) mRNA molecule comprises multiple components -a 5' cap, a protein-coding sequence flanked by 5' and 3' untranslated regions (UTRs), and a 3' poly(A) tail. 
Each of these components can be modified to enhance the intracellular stability, biocompatibility, and translational capacity of the mRNA. ${ }^{22}$ Systematic efforts have revealed strategies for optimizing the $5^{\prime}$ cap, ${ }^{28}$ the $5^{\prime}$ UTR, ${ }^{29,30}$ the $3^{\prime}$ UTR, ${ }^{30,31}$ and the poly(A) tail length. ${ }^{32}$ For the coding sequence, codon optimization has been shown to improve the translatability and structural stability of mRNA molecules. ${ }^{33,34}$ Furthermore, chemical base modification has been shown to enhance mRNA translation while simultaneously reducing immune activation. ${ }^{35-38}$ However, differing approaches to mRNA codon optimization, ${ }^{22}$ coupled with conflicting reports that suggest chemical base modification may not even be necessary for applications requiring repeat dosing, ${ }^{34}$ have contributed to ongoing debate around which mRNA engineering strategies are most effective. To this end, we sought to investigate the efficacy of different codon optimization and base modification strategies in vitro using luciferase reporter mRNAs (Figure 1A). We subsequently applied our findings to the engineering of NPC1 mRNA, with a view to investigating whether exogenous mRNA might be useful for the replacement of NPC1 protein in patient fibroblasts. To the best of our knowledge, this is the first demonstration of engineered mRNA being used to correct NP-C1 disease in vitro.

A 5' cap1 5' UTR Luciferase coding sequence 3' UTR Poly(A) tail

Codon optimization

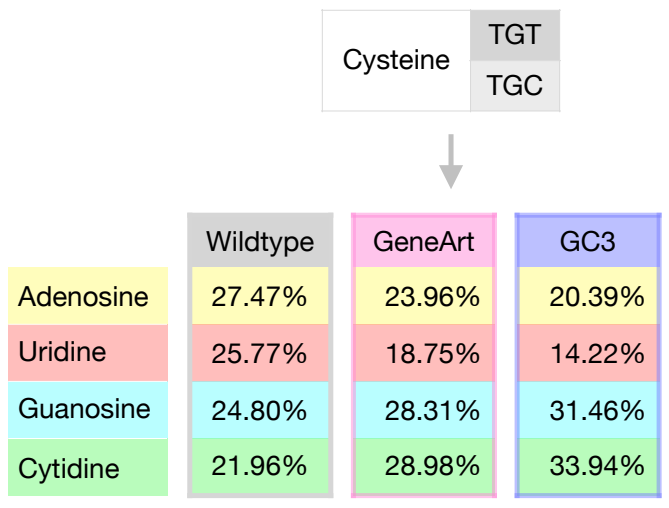

\section{Base modification}
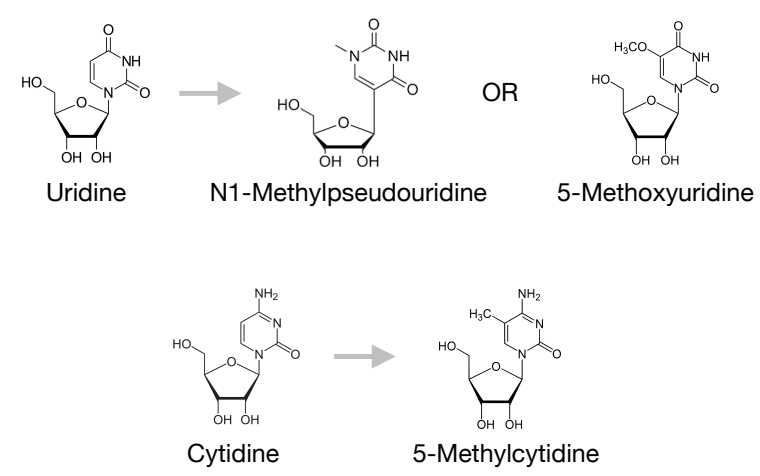

B

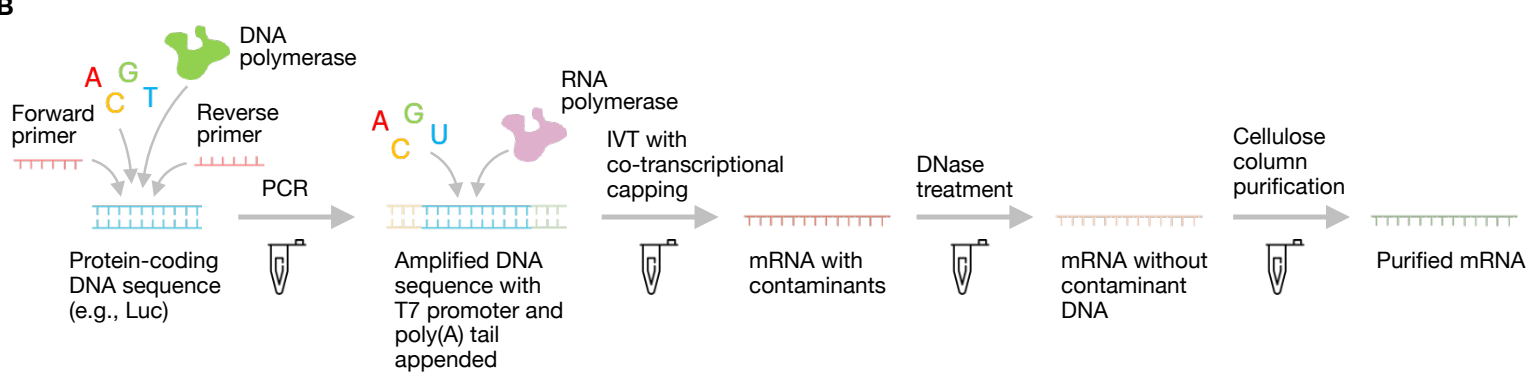

\section{Figure 1. Overview of mRNA engineering workflow}

(A) Codon optimization and chemical base modification are two separate engineering strategies that can be used to enhance mRNA translation. Different codon optimization strategies alter the base content of an mRNA coding sequence in different ways. GC3 optimization results in a significant overall enrichment in $G$ and $C$ base content. (B) An overview of the mRNA synthesis and purification workflow used throughout this study. 


\section{Materials and Methods Cell culture}

HeLa, U87 MG and Hep G2 cells (ATCC) were cultured in Dulbecco's Modified Eagle's Medium (DMEM; Lonza) supplemented with 10\% fetal bovine serum (FBS; Bovogen), $100 \mathrm{U} / \mathrm{ml}$ penicillin and $100 \mu \mathrm{g} / \mathrm{ml}$ streptomycin (Thermo Fisher Scientific). Healthy human control fibroblasts (GM03652G) and NP-C1 patient fibroblasts (GM18393 and GM17919A) were purchased from the Coriell Cell Repository (Table S1) and cultured in DMEM (Lonza) supplemented with 20\% FBS (Bovogen), 100 $\mathrm{U} / \mathrm{ml}$ penicillin and $100 \mu \mathrm{g} / \mathrm{ml}$ streptomycin (Thermo Fisher Scientific). For cholesterol esterification assays, fibroblasts were switched to DMEM supplemented with $5 \%$ fetal bovine lipoprotein deficient serum (Alpha Diagnostic International), $100 \mathrm{U} / \mathrm{ml}$ penicillin and $100 \mu \mathrm{g} / \mathrm{ml}$ streptomycin. All cell lines were incubated at $37^{\circ} \mathrm{C}$ with $5 \% \mathrm{CO}_{2}$.

\section{mRNA sequence engineering}

Codon optimization was implemented to enhance the translatability and structural stability of synthesized mRNAs. The GeneArt-optimized luciferase coding sequence was obtained by inputting the wildtype sequence into the online GeneOptimizer portal (Thermo Fisher Scientific). The GC3optimized luciferase coding sequence was obtained by substituting, wherever possible, wildtype codons with codons that had a $\mathrm{G}$ or $\mathrm{C}$ at the third base position. All NPC1 mRNA variants were also codon optimized in the same way (GC3 optimization). This strategy is based on evidence that such codon bias confers enhanced stability and translatability to mRNAs in humans. ${ }^{39}$ Detailed codon selection parameters are available in Supplementary Information (Table S2). All mRNAs harbored an EEF1B2-001 5' UTR upstream of the open reading frame, and an alpha-1 globin 3' UTR and 100-nt poly(A) tail downstream of the open reading frame. These sequences have been shown to further enhance the stability and translatability of IVT mRNAs across multiple cell types. ${ }^{30,40}$

\section{Generation of DNA templates for in vitro transcription}

Wildtype, GeneArt and GC3 luciferase variants were ordered as separate GenParts DNA fragments (Genscript). The GC3-optimized NPC1 sequence was encoded in a plasmid (Twist Bioscience) and linearized via double restriction enzyme digestion using BamHI-HF (NEB) and HindIII-HF (NEB). Successful linearization was confirmed via $1 \%$ agarose gel electrophoresis. Templates for IVT were generated by performing high-fidelity PCR using Q5 Hot Start High-Fidelity DNA Polymerase (NEB) and primers 1 and 2 (IDT; sequences provided in Table S3). From 5' to 3', each double-stranded DNA template contained a T7 promoter, a 5' UTR, open reading frame, 3' UTR, and 100-nt poly(A) sequence (introduced via primer 2). After linearization and PCR amplification steps, DNA products were purified using the DNA Clean \& Concentrator-5 Kit (Zymo Research). All purified PCR products were visually checked for expected size via $1 \%$ agarose gel electrophoresis and assessed for purity and yield via Nanodrop (Thermo Fisher Scientific).

\section{mRNA synthesis and purification}

mRNAs were transcribed from DNA templates using T7 RNA polymerase (HiScribe T7 High Yield RNA Synthesis Kit, NEB). To generate base modified mRNA variants, where specified uridine 5' triphosphate (UTP) was completely replaced with either N1-methylpseudouridine 5'-triphosphate (M14TP, APEXBIO) or 5-methoxyuridine 5'-triphosphate (5moUTP, APExBIO), and cytidine 5'triphosphate (CTP) was completely replaced with 5-methylcytidine 5'-triphosphate (5mCTP, APExBIO). Co-transcriptional capping was performed using the EZ Cap Reagent AG (3' OMe) (APExBIO), resulting in a stable Cap1 structure at the $5^{\prime}$ end of synthesized mRNA transcripts. After IVT reactions had run to completion, DNA templates were digested using DNase I (NEB). mRNAs were subsequently purified using a protocol that has been described previously (Figure 1B). ${ }^{41}$ Purified mRNA was suspended in $1 \mathrm{mM}$ sodium citrate, pH 6.5 (THE RNA Storage Solution, Thermo Fisher Scientific). mRNA integrity was assessed via gel electrophoresis by running denatured 
aliquots on a non-denaturing $1 \%$ agarose gel, using SYBR Safe DNA Gel Stain (Thermo Fisher Scientific) to visualize bands. mRNA concentration and purity were assessed via Nanodrop (Thermo Fisher Scientific).

\section{Luciferase assay}

Cells were seeded at varying densities in white, flat bottom 96-well plates (Corning). The next day, mRNA was complexed with Lipofectamine MessengerMax (Thermo Fisher Scientific) in Opti-MEM I Reduced Serum Medium (Thermo Fisher Scientific) according to the manufacturer's instructions, using $2 \mu$ l Lipofectamine reagent per $\mu \mathrm{g}$ of mRNA. Complexed mRNA was added to cells in serumcontaining culture medium. At various timepoints post-transfection $(6,24$ or $48 \mathrm{~h})$, plates were retrieved from the incubator and allowed to equilibrate to room temperature, before reconstituted luciferase reagent (ONE-Glo EX, Promega) was added to cells in culture medium, following the manufacturer's protocol. Plates were incubated at room temperature for 2-3 min with moderate shaking to facilitate cell lysis and sample equilibration. Luminescence was subsequently measured using an Infinite M200 Pro plate reader (Tecan).

\section{In silico prediction of mRNA secondary structures}

mRNA secondary structures were predicted by inputting mRNA sequences into the RNAfold webserver provided by the Vienna RNA Websuite. ${ }^{42}$ RNAfold computes the minimum free energy (MFE) and optimal secondary structure for a given sequence using experimentally determined thermodynamic parameters. Default RNA parameters from the 2004 Turner model were used to generate secondary structure predictions. ${ }^{43}$

\section{Determination of mRNA melting curves via differential scanning fluorimetry}

mRNA thermal stability was assessed via differential scanning fluorimetry according to a previously published protocol. ${ }^{44}$ Briefly, $1 \mu \mathrm{g}$ aliquots of mRNA were mixed with Quant-iT RiboGreen RNA reagent (Thermo Fisher Scientific) and brought to a final volume of $50 \mu$ with nuclease-free water, such that the final RiboGreen concentration was 1X. Samples were added to separate wells of a 48well PCR plate (Bio-Rad) and incubated in a MiniOpticon Real-Time PCR System (Bio-Rad). A melting curve routine was initiated, whereby samples were incubated at $20^{\circ} \mathrm{C}$ for $3 \mathrm{~min}$, followed by heating at a constant rate from 20 to $90^{\circ} \mathrm{C}$. Fluorescence intensities were recorded at each incremental temperature using the excitation and emission settings for SYBR Green (since RiboGreen and SYBR Green have very similar spectral properties). Once the temperature reached $90^{\circ} \mathrm{C}$, samples were cooled to $20^{\circ} \mathrm{C}$ and allowed to refold for $15 \mathrm{~min}$, at which point the melting curve routine was repeated. Heating and cooling cycles were performed 3 times consecutively, with all samples measured in duplicate. The negative first derivative of fluorescence intensities were then analyzed as a function of temperature.

\section{NPC1 immunofluorescence staining}

Cells were seeded at a density of 3000 cells/well in black, clear-bottom CellCarrier-96 Ultra microplates (PerkinElmer). The next day, cells were transfected with NPC1 mRNA using Lipofectamine MessengerMax reagent, as described above. $24 \mathrm{~h}$ after transfection, cells were fixed in $4 \%$ paraformaldehyde for $20 \mathrm{~min}$ at room temperature, washed with PBS, and permeabilized for 1 $\mathrm{h}$ with $0.2 \%$ saponin (Sigma-Aldrich) diluted in PBS containing 10\% normal goat serum (Thermo Fisher Scientific). Cells were then incubated for $1 \mathrm{~h}$ at room temperature with anti-NPC1 primary antibody (ab134113, Abcam) diluted 1:200 in PBS containing 0.2\% saponin and 10\% normal goat serum. Cells were subsequently washed with PBS containing $0.1 \%$ Tween 80 , and incubated for $1 \mathrm{~h}$ with Alexa Fluor 488-labelled goat anti-rabbit secondary antibody (Thermo Fisher Scientific) diluted $1: 500$ in PBS containing $0.2 \%$ saponin and $10 \%$ normal goat serum. After washing with $0.1 \%$ Tween 80, cells were stained 1:10000 with Hoechst 33342 (Thermo Fisher Scientific) for 10 min, washed 
once with PBS, and stored in PBS at $4^{\circ} \mathrm{C}$ until required for imaging. Cells were imaged using a PerkinElmer Operetta CLS High Content Imaging System with a 20X high numerical aperture dry objective lens and AF488 and DAPI filter sets. At least 7 imaging fields were analyzed per well, and every experimental condition was run in triplicate, equating to an analysis of $>300$ cells per treatment condition. Images were analyzed using a custom analysis sequence in the PerkinElmer Harmony High-Content Imaging and Analysis Software. Briefly, nuclei were segmented and counted based on Hoechst staining intensities, and intracellular NPC1 staining intensities in each well were separately quantified using the AF488 channel; the resulting per well AF488 intensity values were divided by the number of nuclei in each well to yield the average NPC1 fluorescence per well.

\section{Amplex Red unesterified cholesterol assay}

Cells were seeded at a density of 3000-5000 cells/well in CellCarrier-96 Ultra microplates in DMEM containing 20\% FBS. After $24 \mathrm{~h}$, cells were transfected with NPC1 mRNA using Lipofectamine MessengerMax reagent, as described above. 24 or $48 \mathrm{~h}$ after transfection, the cell culture medium was removed and cells were washed in PBS twice, before $100 \mu$ reconstituted Amplex Red cholesterol assay reagent (Thermo Fisher Scientific), excluding cholesterol esterase, was added to each well as per the manufacturer's instructions. After incubation at $37^{\circ} \mathrm{C}$ for $1 \mathrm{~h}$, the fluorescence intensity in each well was measured $(E x=560 \mathrm{~nm} ; E m=590 \mathrm{~nm})$ using an Infinite M200 Pro plate reader.

\section{alamarBlue cell viability assay}

mRNA transfections were carried out in 96-well plates, as described above. 24 or $48 \mathrm{~h}$ after transfection, alamarBlue cell viability reagent (Thermo Fisher Scientific) was added to the cell culture medium in a 1:10 ratio (alamarBlue: DMEM), as per the manufacturer's instructions. Cells were incubated at $37^{\circ} \mathrm{C}$ in the dark for between $1-4 \mathrm{~h}$, and then the fluorescence intensity in each well was measured $(E x=560 \mathrm{~nm} ; E m=590 \mathrm{~nm})$ using an Infinite M200 Pro plate reader.

\section{Cholesterol esterification assay}

Cells were seeded in CellCarrier-96 Ultra microplates at a density of 3000-5000 cells/well in DMEM containing $20 \%$ FBS. The next day, cells were switched to DMEM containing $5 \%$ fetal bovine lipoprotein deficient serum. After $24 \mathrm{~h}$, cells were transfected with NPC1 mRNA using Lipofectamine MessengerMax reagent, as described above. $24 \mathrm{~h}$ after transfection, the culture medium was replaced with either Opti-MEM or Opti-MEM spiked with $50 \mu \mathrm{g} / \mathrm{ml}$ LDL. After a further $6 \mathrm{~h}$, intracellular levels of unesterified cholesterol and total cholesterol were separately assayed using the Amplex Red Cholesterol Assay Kit (Promega), following the manufacturer's instructions. Levels of esterified cholesterol were calculated by subtracting the amount of esterified cholesterol from the total cholesterol amount. The addition of LDL after $48 \mathrm{~h}$ of sterol depletion provides a source of cholesterol that can be used by cells for esterification. While healthy cells are expected to demonstrate a burst of cholesterol esterification in response to this, NP-C patient cells tend to show low levels of esterification regardless of how much cholesterol is available.

\section{Filipin staining}

The same protocol was followed as in the cholesterol esterification assay above. After the $6 \mathrm{~h}$ incubation with $50 \mu \mathrm{g} / \mathrm{ml}$ LDL or Opti-MEM alone, cells were fixed in $4 \%$ paraformaldehyde for 20 min at room temperature and then washed with PBS. Cells were subsequently stained with $50 \mu \mathrm{g} / \mathrm{ml}$ filipin (Sigma-Aldrich; freshly dissolved in DMSO at $10 \mathrm{mg} / \mathrm{ml}$ and then diluted in PBS) in the dark at room temperature for $1 \mathrm{~h}$. After washing, cells were stored in PBS at $4^{\circ} \mathrm{C}$, and later imaged using a PerkinElmer Operetta with a 20X high numerical aperture dry objective lens and the DAPI filter set. At least 9 imaging fields were analyzed per well, and every experimental condition was run in triplicate, equating to an analysis of $>600$ cells per treatment condition. Images were analyzed using a custom 
analysis sequence in the PerkinElmer Harmony High-Content Imaging and Analysis Software. Intracellular filipin staining intensities in each well were quantified using the DAPI channel.

\section{Lysotracker Red staining}

The same protocol was followed as in the cholesterol esterification assay above. After the $6 \mathrm{~h}$ incubation with $50 \mu \mathrm{g} / \mathrm{ml}$ LDL or Opti-MEM alone, cells were live-stained with $50 \mathrm{nM}$ Lysotracker Red DND-99 (Thermo Fisher Scientific) in Opti-MEM at $37^{\circ} \mathrm{C}$ for $1 \mathrm{~h}$. Cells were subsequently washed with PBS, fixed in 4\% paraformaldehyde, and stained with 1:10,000 Hoechst 33342, before being stored in PBS at $4^{\circ} \mathrm{C}$. Imaging was performed using a PerkinElmer Operetta with a 40X high numerical aperture dry objective lens and TRITC and DAPI filter sets. At least 9 imaging fields were analyzed per well, and every experimental condition was run in duplicate, equating to an analysis of $>300$ cells per treatment condition. To measure lysosome size, images were analyzed using a custom analysis sequence in the PerkinElmer Harmony High-Content Imaging and Analysis Software. Briefly, Lysotracker-stained cellular regions were identified and segmented, and the areas of the selected regions were measured and summed for each well.

\section{Statistics}

Experimental data were analyzed used Prism 9 Software (GraphPad), by either ordinary one-way ANOVA with a Dunnett's multiple comparisons test, or two-way ANOVA with a Tukey's multiple comparisons test.

\section{Results \\ "GC3" codon optimization enhances mRNA translation, in part due to increased mRNA structural stability}

An mRNA molecule's competence for protein translation is governed by two factors: functional halflife and translational efficiency. ${ }^{33}$ The former is defined by the length of time within which an mRNA molecule is capable of generating protein, while the latter is defined by the mRNA's ability to recruit ribosomes to initiate translation. The coding sequence plays an important role in shaping both of these factors, and thus governs an mRNA's translatability to a considerable extent. Codon optimization, the process of replacing wildtype codons with more "optimal" synonymous codons, is a well-known and widely used strategy for enhancing the expression of protein-coding genes. ${ }^{45}$ However, specific strategies for codon optimization vary considerably based on different underlying assumptions about which codon features are important for translation. One approach involves substituting in the most frequently used codon for all instances of a given amino acid. ${ }^{46}$ Another approach involves only replacing rare codons with more abundant synonymous codons. ${ }^{47}$ Still other approaches involve adjusting the codon usage frequency to match the natural frequencies in a host organism, ${ }^{48,49}$ or choosing codons based on cognate transfer RNA (tRNA) abundance..$^{50}$ Many available codon optimization algorithms involve a weighted combination of two or more different optimization parameters. ${ }^{46,49,51}$

A recent study by Hia et al. revealed that human mRNAs comprising codons with $\mathrm{G}$ or $\mathrm{C}$ at the third base position (GC3) are associated with increased stability relative to mRNAs harboring codons with either $\mathrm{A}$ or $\mathrm{U}$ at the third base position. ${ }^{39}$ They proposed that GC3 codons contribute to mRNA stability in part by preventing interactions with RNA-binding proteins that typically act to induce transcript decay (such as ILF2 and ILF3). ${ }^{39}$ In light of this finding, as well as other corroborating reports, ${ }^{34,52}$ we sought to explore whether GC3 optimization is a viable strategy for enhancing heterologous mRNA expression in vitro. To this end, we engineered a firefly luciferase (Luc) coding sequence based on the GC3 optimization strategy, globally optimizing every amino acid in the sequence. Where 2 or more synonymous GC3 codons existed, we made our selection on the basis of which codon had the highest human codon usage frequency. We sought to compare the 
expression profile of GC3-optimized Luc to wildtype Luc, as well as a Luc variant optimized by a different codon optimization strategy (for the purpose of this study, we used the GeneOptimizer algorithm provided by Thermo Fisher via its GeneArt gene synthesis service). ${ }^{51}$ The GeneOptimizer algorithm takes a multiparameter sliding-window approach to codon optimization, balancing various considerations including GC content, DNA motifs, and codon usage. We designed all 3 mRNAs to harbor a Cap1 structure and EEF1B2-001 5' UTR immediately upstream of the coding sequence, and an alpha-1 globin 3' UTR and 100-nt poly(A) tail downstream. Both the EEF1B2-001 5' UTR and alpha-1 globin 3' UTR were chosen based on previous reports that showed their inclusion significantly enhanced mRNA stability and expression in vitro. ${ }^{30,40}$

We initially produced the 3 Luc mRNAs using all unmodified nucleotides, following a uniform synthesis and purification protocol (Figure 1B). After transfecting 3 different cell lines (we used 3 different cell lines to ensure that our findings were not cell line-specific), we observed that both codon-optimized Luc variants consistently outperformed wildtype Luc by more than an order of magnitude (Figure 2A). However, we observed no meaningful difference in expression profiles between the 2 codon optimization strategies. Given that base modification has been shown to enhance mRNA translation while reducing immune activation, ${ }^{35,53}$ we next investigated the expression profiles of the 3 Luc variants when uridine triphosphate (UTP) was globally replaced with N1-methylpseudouridine triphosphate (M1 $\psi$ TP). Again, we observed that both codon-optimized variants outperformed wildtype Luc across the 3 different cell lines, while all three variants outperformed their unmodified counterparts (Figure 2B). This time, however, we observed that GC3optimized Luc produced meaningfully greater protein expression than GeneArt-optimized mRNA.

A
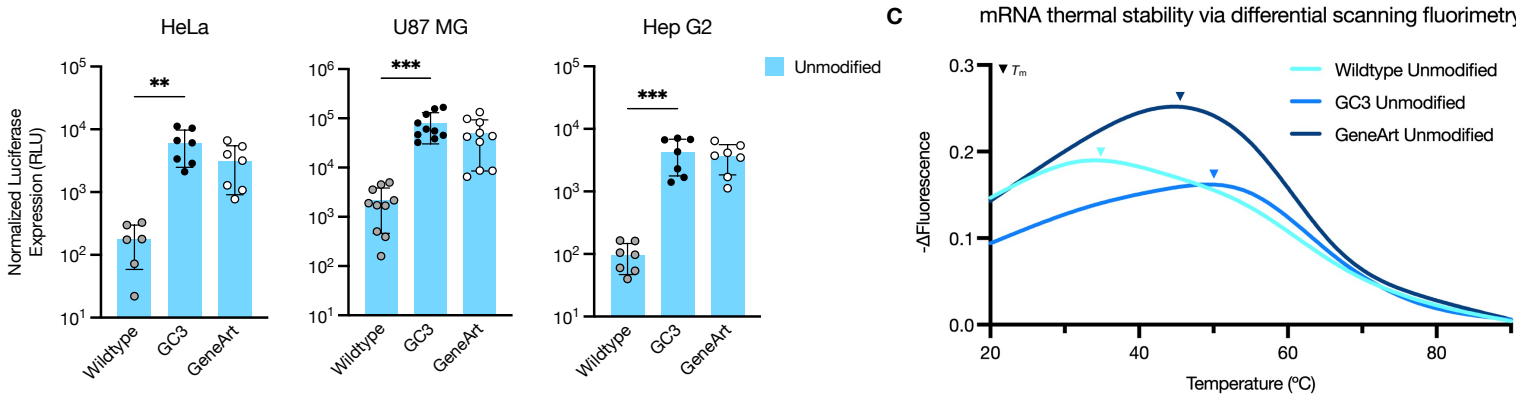

B
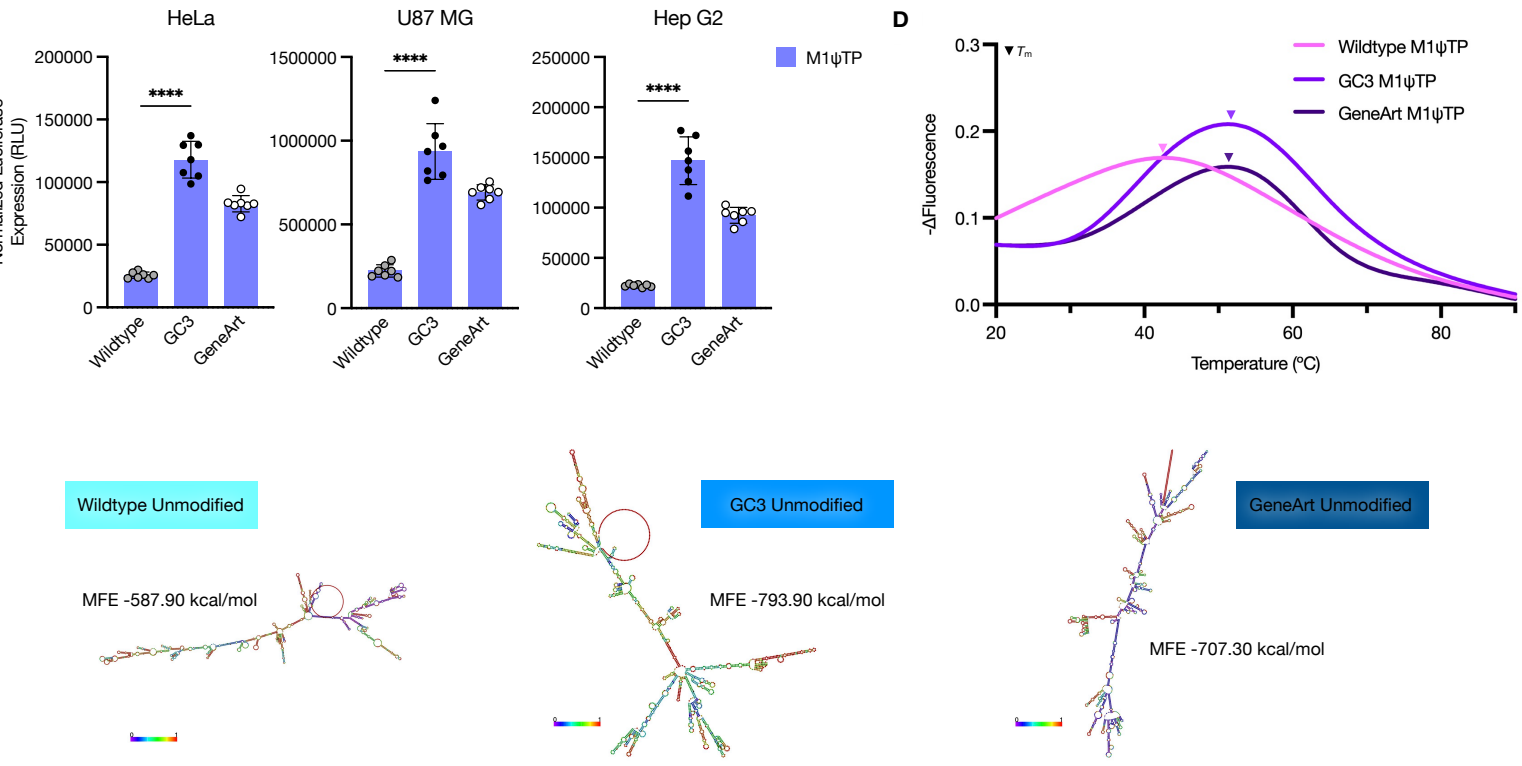


\section{Figure 2. In vitro expression and thermal stability profiles of wildtype versus codon-optimized Luc mRNAs}

(A) Luciferase expression profiles for Luc mRNA variants harboring all unmodified bases, across HeLa, U87 MG, and Hep G2 cell lines. (B) Protein expression profiles for N1-methylpseudouridine triphosphate (M1 $\psi$ TP) base-modified Luc mRNA variants, across HeLa, U87 MG, and Hep G2 cell lines. (C, D) Thermal stability curves for unmodified and M1 $\psi$ TP-modified mRNA variants, as measured by differential scanning fluorimetry. Curves were generated by plotting the negative first derivative of the fluorescence trace as a function of temperature. mRNA melting temperature is denoted by the $\boldsymbol{\nabla}$ icon. (E) RNAfold predictions of optimal secondary structure and minimum free energy for unmodified mRNA variants. Colors indicate base-pairing probabilities, with blue indicating lower probability. In (A) and (B), cells were seeded at a density of 10,000 per well, transfected with $200 \mathrm{ng}$ mRNA, and assayed for protein expression $24 \mathrm{~h}$ after treatment. Data are mean $\pm \mathrm{s}$.d. of at least three independent experiments and were analyzed by ordinary one-way ANOVA followed by a Dunnett's multiple comparisons test. ${ }^{\star \star} P<0.01,{ }^{* \star *} P<0.001$, and ${ }^{\star \star \star \star} P<0.0001$. In (C), all mRNAs were measured in duplicate and for three consecutive heating/cooling cycles. Three independent runs were performed. Curves represent the mean of all independent runs, using data taken from the second heating/cooling cycle.

Having confirmed that GC3 optimization is a viable strategy for enhancing mRNA translation in vitro, we next sought to investigate why this might be the case. A previous report by Mauger et al. showed that increased mRNA secondary structure leads to enhanced protein expression via an increase in mRNA functional half-life. ${ }^{33}$ Since an mRNA's GC content tends to be positively correlated with its degree of secondary structure, we probed whether GC3 optimization enhances the secondary structure of Luc mRNA. We used differential scanning fluorimetry, a validated technique that uses an RNA-specific fluorescent reporter dye to measure the structural stability of RNA constructs in the presence of altered environmental parameters such as temperature, salts or $\mathrm{pH}^{4}{ }^{44}$ We generated melt curves for the different mRNA variants, measuring each variant during three consecutive cycles of gradual heating from $20^{\circ} \mathrm{C}$ to $90^{\circ} \mathrm{C}$ followed by gradual cooling back to $20^{\circ} \mathrm{C}$. Using data from the second heating/cooling cycle (due to the greater consistency of the data across several experimental runs compared to the first and third cycles), we determined the peak melting temperature $\left(T_{\mathrm{m}}\right)$ for each variant. Consistent with the protein expression data, we observed that both GeneArt unmodified Luc and GC3 unmodified Luc underwent melting at considerably higher temperatures $\left(\sim 46^{\circ} \mathrm{C}\right.$ and $\left.\sim 51^{\circ} \mathrm{C}\right)$ than unmodified wildtype Luc $\left(\sim 35^{\circ} \mathrm{C}\right)$, indicating greater mRNA structural stability (Figure $2 \mathrm{C}$ ). This trend also held for M1 1 TP modified constructs, although base modification appeared to dramatically increase the $T_{\mathrm{m}}$ of wildtype Luc $\left(\sim 35^{\circ} \mathrm{C}\right.$ to $\left.\sim 43^{\circ} \mathrm{C}\right)$ while inducing a much less significant increase for codon-optimized mRNAs (Figure 2D). An estimation of the minimum free energy (MFE) and optimal secondary structure of the unmodified Luc variants using the RNAfold webserver $^{42}$ further corroborated these findings (Figure 2E), with wildtype Luc estimated to have a considerably higher MFE than GeneArt and GC3 Luc (a lower MFE indicates greater structural stability). Together, these data suggest that codon optimization-and in particular GC3 optimization-results in increased mRNA stability due to an increase in secondary structure, and that this may play an important role in enhancing protein expression. The possible mechanism(s) by which mRNA secondary structure enhances translation have been discussed elsewhere. ${ }^{33}$

\section{GC3 codon optimization and N1-methylpseudouridine base substitution synergistically enhance mRNA translation}

Next, we investigated the impact of different mRNA base modification strategies on protein expression in vitro. M1 $\psi$ TP and 5-methoxyuridine triphosphate (5moUTP) are among the most commonly used UTP substitutes, while 5-methylcytidine triphosphate (5mCTP) is sometimes used in place of cytidine triphosphate (CTP) and in combination with M1 $\psi$ TP..$^{53,54}$ Thus, we engineered GC3 
and GeneArt Luc mRNAs each with 4 different base compositions: (1) all unmodified bases, (2) 5 moUTP in place of UTP, (3) M1 $\psi$ TP in place of UTP, and (4) M1 $\psi$ TP in place of UTP and 5mCTP in place of CTP. We transfected HeLa, U87 MG and Hep G2 cells with these 8 mRNA variants and assayed Luc expression at $24 \mathrm{~h}$. All 3 cell lines exhibited relatively uniform expression profiles, with the different base modification strategies ranking, in order of Luc expression from highest to lowest, M1 1 TP $>5$ moUTP $>$ M1 $\psi$ TP +5 mCTP $>$ unmodified (Figure 3A). We observed that the combination of GC3 codon optimization with M1 $\Psi$ TP base modification cumulatively resulted in the highest protein expression across all cell lines. M1 $\Psi$ TP has been shown to enhance mRNA translation by increasing ribosome recruitment and thus improving translational efficiency. ${ }^{35}$ Time course experiments revealed that kinetic Luc expression profiles varied across the three cell lines, with expression peaking at $6 \mathrm{~h}$ in HeLa cells but at $24 \mathrm{~h}$ in U87 MG and Hep G2 cells (Figure S1). Interestingly, although GC3 optimization outperformed GeneArt optimization across both 5moUTP and M1 4 TP modifications, the same did not hold for the 5mCTP base modification strategy (GeneArt optimization outperformed GC3 optimization). The dramatic reduction in expression when 5mCTP was combined with M1 4 TP, relative to $M 1 \psi T P$ alone, has previously been observed in cells and cellfree extracts. ${ }^{35}$ Thus, we conclude that coupling GC3 optimization with M1 $\psi$ TP base modification leads to synergistic enhancement of mRNA translation in vitro. In our hands, this combination generated an mRNA that was approximately 1000 -fold more potent than wildtype, unmodified Luc mRNA (Figure 3B).

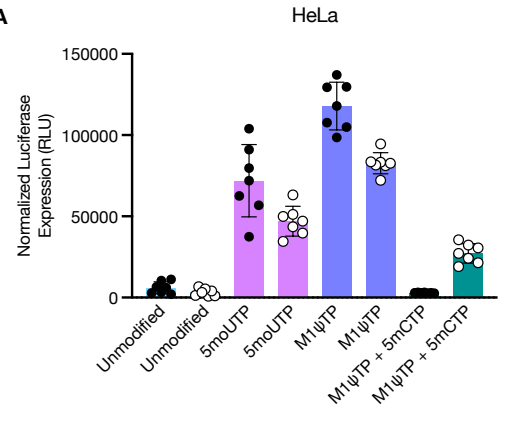

B

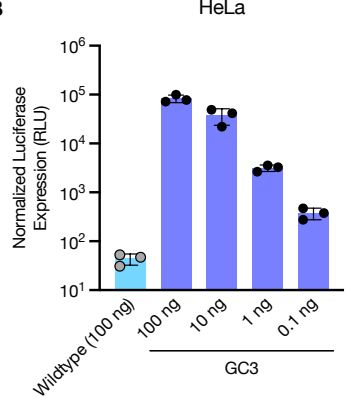

U87 MG

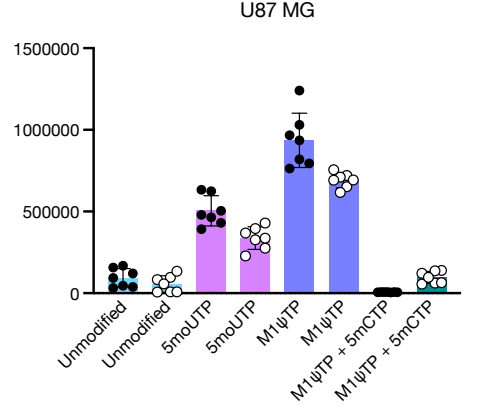

U87 MG

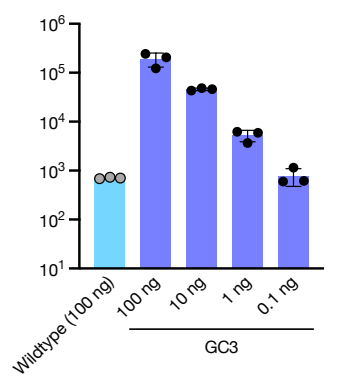

Hep G2

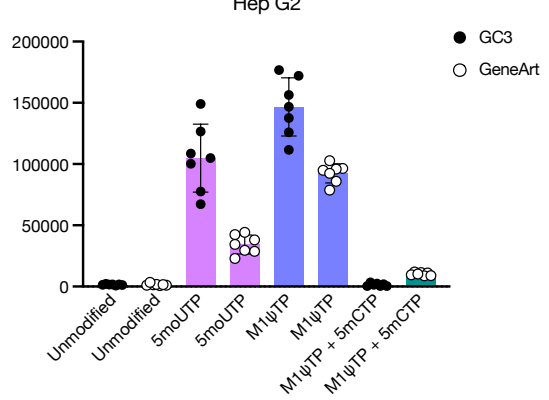

Hep G2

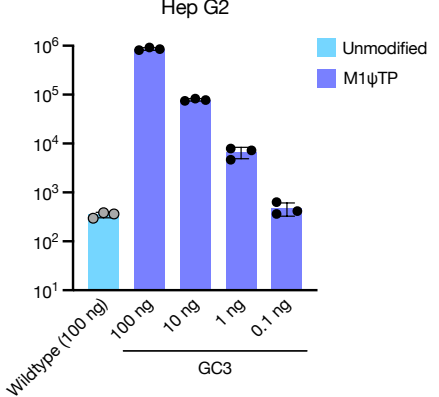

Figure 3. In vitro expression profiles for codon-optimized Luc mRNAs harboring different base modifications

(A) Protein expression profiles for GC3-optimized and GeneArt-optimized Luc mRNAs harboring either all unmodified bases, M1 4 TP-modified bases, 5moUTP-modified bases, or M1 1 TP- and 5mCTP-modified bases. Expression was assayed across HeLa, U87 MG, and Hep G2 cell lines. (B) Protein expression profiles for GC3-optimized, M1 4 TP-modified Luc mRNA at $100 \mathrm{ng}, 10 \mathrm{ng}, 1 \mathrm{ng}$, and $0.1 \mathrm{ng}$, compared to wildtype, unmodified Luc mRNA at $100 \mathrm{ng}$. In (A), cells were seeded at a density of 10,000 per well, transfected with $200 \mathrm{ng}$ mRNA, and assayed for protein expression after $24 \mathrm{~h}$. Data are mean \pm s.d. of at least three independent experiments. In (B), HeLa and U87 MG cells were seeded at a density of 10,000 per well, while Hep G2 cells were seeded at a density of 15,000 per well. Protein expression was assayed $24 \mathrm{~h}$ post-transfection. Data are mean \pm s.d. of three technical replicates, from one representative of three independent experiments. 
bioRxiv preprint doi: https://doi.org/10.1101/2022.02.21.479058; this version posted February 24, 2022. The copyright holder for this preprint (which was not certified by peer review) is the author/funder, who has granted bioRxiv a license to display the preprint in perpetuity. It is made available under aCC-BY-ND 4.0 International license.

\section{Engineered NPC1 mRNA restores functional protein expression and reverses disease pathology in NP-C1 patient fibroblasts}

Having successfully engineered a highly expressing Luc mRNA, we next sought to apply our findings to the engineering of NPC1 mRNA (Figure 4A). We performed GC3 optimization of the NPC1 coding sequence and appended the same 5' and 3' flanking regions as before to enable efficient protein expression. We synthesized 3 NPC1 mRNA variants, all comprising identical sequences but utilizing different base compositions (unmodified, M1 4 TP-modified, and 5moUTP-modified), to test whether the same trend that we observed in reporter assays extended to a human in vitro disease model. We did not synthesize constructs with $5 \mathrm{mCTP}$ due to the dramatic decrease in overall expression that we observed in Luc reporter assays when $5 \mathrm{mCTP}$ base modification was combined with M1 4 TP modification. To determine whether the NPC1 mRNA constructs could induce functional protein expression in vitro, we transfected them into human fibroblasts derived from two clinically affected NP-C1 patients (GM18393 and GM17919), both which were previously shown to harbor compound heterozygous mutations at the NPC1 gene locus, with different exons affected for each donor. All 3 NPC1 mRNA variants generated significantly increased protein expression in both cell lines compared to the Lipofectamine-treated control, as measured by high-content widefield fluorescence imaging (Figures 4B, S2A and S2B). Having established that all 3 mRNA variants could induce significant NPC1 protein expression in vitro, we performed all subsequent experiments using NPC1 M1 1 TP mRNA alone due to our previous findings with the Luc mRNA variants. Additionally, due to an insufficiency of GM17919 cells (the growth and viability of these cells became compromised during passaging, despite supplementation with $20 \%$ FBS), we performed all further experiments with only GM18393 cells. Automated quantification of NPC1 protein expression via PerkinElmer Harmony High-Content Imaging and Analysis Software revealed that treatment with NPC1 M1 4 TP mRNA boosted NPC1 protein levels to the same as those observed in healthy, wildtype donor fibroblasts (Figure 4C).

A

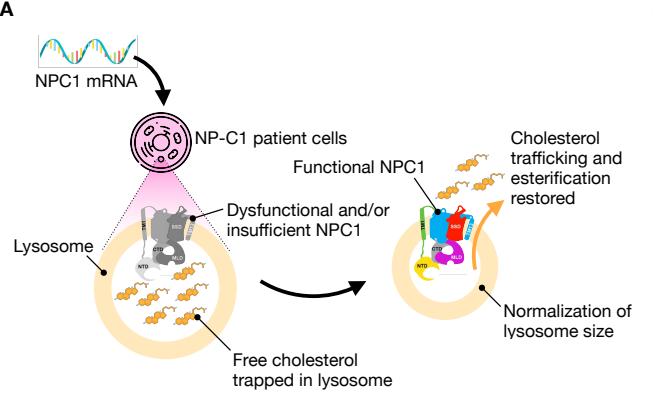

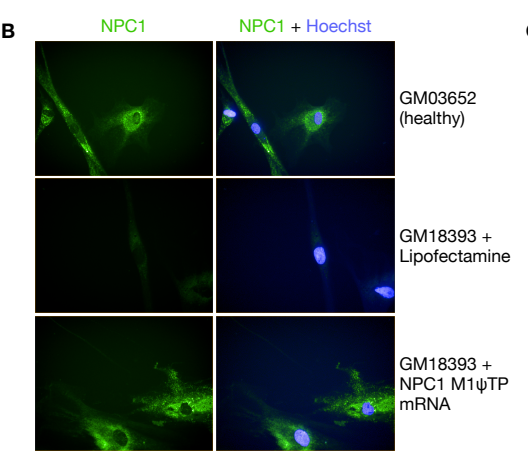

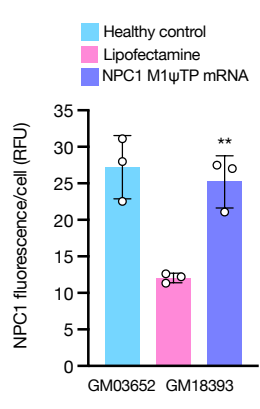

48h incubation in media containing lipoprotein-deficient serum followed by $6 \mathrm{~h}$ incubation with $50 \mu \mathrm{g} / \mathrm{ml} \mathrm{LDL}$

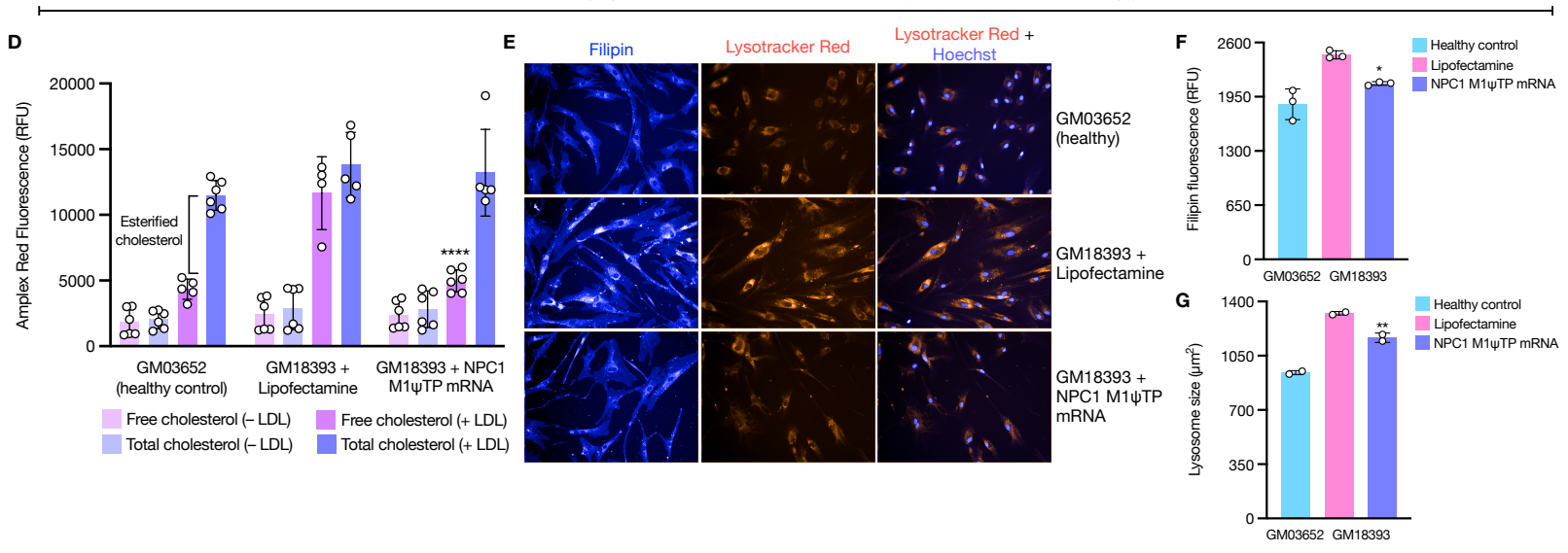




\section{Figure 4. mRNA treatment rescues NPC1 protein insufficiency and the disease phenotype in patient fibroblasts}

(A) Overview of the rationale behind mRNA-based treatment of NP-C1 disease. (B) NPC1 and Hoechst 33342 staining in healthy fibroblasts (GM03652), Lipofectamine-treated patient fibroblasts (GM18393), and GM18393 patient fibroblasts treated with 50 ng of M1 4 TP-modified NPC1 mRNA. Cells were seeded at a density of 3000 per well and imaged $24 \mathrm{~h}$ after treatment. Images are representative of three independent experiments. (C) Quantification of NPC1 staining from the experiment in (B), as measured by average NPC1 fluorescence per cell (cumulative NPC1 fluorescence was divided by the total number of cells identified via Hoescht staining, using the PerkinElmer Harmony high-content analysis software). Data are mean \pm s.d. of three technical replicates (from one representative of three independent experiments), encompassing 7 imaging fields per well and $>300$ cells per treatment condition. (D) Quantification of total and unesterified cholesterol levels in healthy cells, Lipofectamine-treated GM18393 cells, and GM18393 cells treated with $50 \mathrm{ng}$ NPC1 M1 4 TP mRNA, after a $48 \mathrm{~h}$ incubation in lipoprotein-deficient serum followed by either a $6 \mathrm{~h}$ incubation with $50 \mu \mathrm{g} / \mathrm{ml} \mathrm{LDL}$ or a further $6 \mathrm{~h}$ incubation with lipoprotein-deficient serum to establish a baseline control. Total and unesterified cholesterol levels were assayed using the Amplex Red Cholesterol Assay Kit. Data are mean \pm s.d. of two independent experiments. (E) Filipin and Lysotracker Red DND-99 staining in healthy cells, Lipofectamine-treated GM18393 cells, and 50 ng mRNA-treated GM18393 cells after a $48 \mathrm{~h}$ incubation in lipoprotein-deficient serum followed by 6 $\mathrm{h}$ incubation with $50 \mathrm{\mu g} / \mathrm{ml} \mathrm{LDL}$. Images are representative of three independent experiments. $(F)$ Quantification of filipin staining from the experiment in $(E)$, as measured by average filipin fluorescence per well. Data are mean \pm s.d. of three technical replicates (from one representative of three independent experiments), encompassing 9 imaging fields per well and $>600$ cells per treatment condition. (G) Quantification of lysosome size from Lysotracker Red staining in (E), using the PerkinElmer Harmony high-content analysis software. Data are mean \pm s.d. of two technical replicates (from one representative of three independent experiments), encompassing 9 imaging fields per well and $>300$ cells per treatment condition. In (C), (F) and (G), ${ }^{*} P<0.05$, ${ }^{* \star} P<0.01$ by ordinary one-way ANOVA followed by a Dunnett's multiple comparisons test. In (D), ${ }^{\star \star \star \star} P<0.0001$ by two-way ANOVA followed by a Tukey's multiple comparisons test.

Next, we evaluated whether the mRNA-induced increase in NPC1 protein levels corresponded to phenotypic rescue. Assaying the levels of free, unesterified cholesterol in treated and untreated cells confirmed that the expressed NPC1 protein was functional, since transfected cells showed a clear, albeit modest, reduction in free cholesterol levels at $48 \mathrm{~h}$ post-transfection (Figure S3A). Surprisingly, we observed an inverse dose-response relationship, where a lower mRNA dose ( $25 \mathrm{ng}$ ) corresponded to phenotypic improvement (reduced free cholesterol) whereas a higher mRNA dose (100 ng) produced no such improvement. To further probe the downstream phenotypic consequences of mRNA treatment, we performed a cholesterol esterification assay, which is commonly used to diagnose NP-C. ${ }^{55,56}$ Cells were seeded in full serum media, which was subsequently replaced with media containing lipoprotein-deficient serum the following day; a $48 \mathrm{~h}$ incubation in lipoprotein-deficient serum served to deplete cells of cholesterol, after which $50 \mathrm{ug} / \mathrm{ml}$ LDL was added directly to the cells and incubated for a further $6 \mathrm{~h}$. With LDL supplementation providing a fresh source of cholesterol available for esterification, a comparison of free and total cholesterol levels at the end of $6 \mathrm{~h}$ yielded insight into to how much esterified cholesterol was produced by the cells. Unlike healthy cells, which esterify a considerable proportion of the introduced cholesterol pool, NP-C1 cells are incapable of transporting cholesterol across the lysosomal membrane to be esterified, and thus retain cholesterol only in its free, unesterified form. However, treatment with NPC1 M1 4 TP mRNA 20-24 h prior to LDL supplementation restored the capacity for cholesterol esterification in patient cells, as evidenced by a significant reduction in free cholesterol levels (>57\% reduction compared to lipofectamine-treated control) without a change in 
total cholesterol levels (Figure 4D). Widefield fluorescence imaging analysis corroborated these findings. After carrying out the $48 \mathrm{~h}$ incubation in lipoprotein-deficient serum followed by $6 \mathrm{~h}$ incubation with LDL, we stained cells with either filipin, a dye that binds specifically to free cholesterol, ${ }^{57}$ or Lysotracker Red, a dye that is specific for acidic organelles. While Lipofectaminetreated GM18393 cells showed a stark increase in filipin and Lysotracker Red staining relative to healthy control cells, mRNA treatment caused a clear reduction in staining intensities (Figure 4E). Automated image quantification using the PerkinElmer Harmony High-Content Imaging and Analysis Software confirmed that mRNA treatment caused a statistically significant reduction in filipin intensity, with free cholesterol levels essentially reverting to healthy baseline levels (Figure 4F). We also observed a clear reduction in lysosome size $\left(\sim 157 \mu \mathrm{m}^{2}\right.$ reduction compared to lipofectaminetreated control), similarly measured by automated quantification of Lysotracker Red staining (Figure 4G). Since NP-C1 disease is marked by lysosomal enlargement due to cholesterol entrapment, these data suggest that mRNA treatment causes functional NPC1 protein to be correctly installed in the endo-lysosomal membrane, resulting in the mobilization of trapped cholesterol and normalization of lysosome size. Taken together, our findings show that mRNA treatment has the capacity to rescue NPC1 protein insufficiency and correct the molecular and phenotypic consequences of biallelic NPC1 mutations.

\section{Discussion}

The utility of mRNA as a therapeutic strategy for protein replacement has been demonstrated across a wide array of genetic diseases. ${ }^{24-27,58-64}$ Building upon this body of work, we sought to investigate whether mRNA treatment could correct the biochemical and phenotypic hallmarks of NP-C1 disease in vitro. We first sought to evaluate codon optimization strategies so that we could consistently engineer mRNAs capable of generating high protein expression across multiple cell types. Utilizing the GC3 codon optimization strategy as informed by previous studies, ${ }^{39,65}$ we consistently observed almost two orders of magnitude greater protein expression in a Luc reporter assay compared to wildtype mRNA when all unmodified nucleotides were used (Figure 2A). Protein expression levels generated by GC3-optimized mRNA were comparable to a Luc mRNA variant codon optimized via a different strategy, suggesting that different codon optimization strategies may be valid as a means for enabling therapeutic protein expression. When we paired codon optimization with base modification, however, GC3 optimization combined with M1 $\psi$ TP base modification emerged as the clearly optimal strategy for maximizing protein expression (Figure $3 \mathrm{~A}$ ).

The increased expression capacity of the GC3-optimized mRNA variant appears to be, in large part, a result of the enhanced functional half-life of the mRNA molecule, ${ }^{33}$ which in turn is influenced by its secondary structure. Our data show that GC3 codon optimization enhances mRNA thermal stability via an increase in secondary structure (Figures $2 \mathrm{C}$ and $2 \mathrm{D}$ ), while M1 4 TP base modification also modulates secondary structure and thus thermal stability to a certain extent. The precise relationship between mRNA secondary structure and protein levels remains to be fully elucidated but appears to be governed by multiple mechanisms. GC3 optimization has previously been shown to increase mRNA functional half-life by preventing or reducing interactions with RNA-binding proteins responsible for mRNA degradation, including ILF2 and ILF3 ${ }^{39}$ Additionally, enhanced mRNA secondary structure may increase association with stabilizing RNA-binding proteins. ${ }^{66,67}$ Ribosomal translocation along the open reading frame (ORF) may be positively affected by increased mRNA secondary structure, with both the speed of ribosome movement and frequency of pausing favoring increased protein output versus mRNAs containing a lesser degree of secondary structure. ${ }^{33}$ Finally, the depletion of uridine throughout the ORF as a result of GC3 optimization may further enhance expression by reducing activation of RNA-dependent pathways that lead to inhibition of translation, ${ }^{52}$ such as the RNase L pathway. ${ }^{68}$ Incorporation of M1 $\Psi$ TP further enhances mRNA translatability independent of GC3 optimization, not only by increasing mRNA stability, but also by preventing 
protein kinase R-induced translational repression and by increasing ribosomal density. ${ }^{33,35}$ Conversely, our finding that $5 \mathrm{mCTP}$ base modification severely compromised protein expression, especially when combined with GC3 optimization (Figure 3A), may suggest an adverse effect of $5 \mathrm{mCTP}$ incorporation on mRNA secondary structure and ribosome kinetics. ${ }^{35}$ Together, these observations reveal how GC3 optimization coupled with M1 4 TP base modification synergistically enhance protein production in cells. One practical constraint surrounding the GC3 optimization strategy, however, is that current commercial gene synthesis technologies are often incapable of producing genes with overtly high levels of complexity (i.e., high GC content). In view of this, the GC3 optimization strategy sometimes needs to be tailored to ensure that a fair tradeoff is achieved between compliance with technology constraints, and maintenance of a relatively high degree of mRNA secondary structure and codon optimality.

Having identified a viable strategy for engineering highly-expressing and minimally immunogenic ${ }^{35}$ mRNAs, we next investigated whether engineered NPC1 mRNA could rescue NP-C1 disease in patient fibroblasts. We first assayed NPC1 protein expression $24 \mathrm{~h}$ after mRNA treatment, and observed that all 3 mRNA variants, which differed only in the type of base modification employed (unmodified, M1 1 TP, $5 \mathrm{moUTP}$ ), were able to generate substantial NPC1 protein expression in vitro as determined by widefield fluorescence imaging (Figures 4B, S2A and S2B). Since GC3 M14TP Luc mRNA generated the best dose-response profile in Luc reporter assays, we decided to narrow our focus to this engineering strategy in all subsequent NPC1 experiments. Our finding that treatment with NPC1 M1 $\Psi$ TP mRNA restored NPC1 protein levels to those observed in normal, healthy cells (Figure 4C) encouraged us to assess the phenotypic consequences of mRNA treatment. We evaluated whether NPC1 M1 4 TP mRNA could reduce the levels of free, unesterified cholesterol in affected cells seeded in full serum medium. Although we observed a statistically significant reduction in free cholesterol levels at $48 \mathrm{~h}$ post-treatment (Figure S3A), the change was modest. It is possible that the paucity of phenotypic rescue may have been caused by the rapid growth and division of cells in the time that elapsed after mRNA treatment, especially given the high serum content of the media. It is also possible that the selected timepoint may have been shorter than was necessary to observe a more significant phenotypic change.

More surprising, however, was our finding that only the lowest mRNA dose ( $25 \mathrm{ng})$ had any meaningful impact on free cholesterol levels, whereas higher doses failed to elicit any substantial phenotypic change. This inverse dose-response relationship was also observed in other phenotypic assays. Filipin imaging in the context of a cholesterol esterification assay revealed that whereas the lowest mRNA dose (50 $\mathrm{ng}$ ) yielded a phenotypic improvement (a reduction in filipin levels), the highest mRNA dose (200 ng) produced an increase in filipin staining well above the Lipofectaminetreated control (Figure S3B). (Reasons for differential mRNA dosing between assays include differences in seeding densities, growth medium and assay timepoints.) The worsened phenotype at higher doses may have occurred due to mRNA overdosing. An overabundance of mRNA would be expected to introduce many more transcripts into cells than the ribosomes could reasonably process, resulting in the association between non-ribosome-bound mRNAs and aggregation-prone proteins, and the subsequent formation of stress granules. ${ }^{69}$ Cellular stress has previously been linked to an upregulation in sterol synthesis and cholesterol accumulation. ${ }^{70,71}$ Since cells affected by NP-C1 lack the ability to esterify cholesterol, the increased cholesterol production as a result of cellular stress would be expected to increase the pool of unesterified cholesterol in the lysosome. Further studies would help to elucidate the precise mechanism by which mRNA overdosing leads to an exacerbation of the NP-C1 disease phenotype. It would also be useful to know whether such a phenomenon is generalizable across disparate disease states. 
To further probe whether NPC1 M1 $\Psi$ TP mRNA could rescue the disease phenotype, we subjected cells to a cholesterol esterification assay, depleting cells of cholesterol for an extended period of time before reintroducing cholesterol in the form of LDL and monitoring cholesterol fate after $6 \mathrm{~h}$. Quantification of the levels of free and total cholesterol revealed that, at the appropriate dose, NPC1 M1 $\Psi$ TP mRNA could indeed rescue the disease phenotype, as evidenced by a normalization in the levels of esterified cholesterol where minimal capacity for esterification had previously been observed (Figure 4D). Filipin and Lysotracker Red imaging corroborated these findings (Figure 4E), and quantification of filipin levels and lysosome size (the latter of which was measured by tracing the cell regions stained by Lysotracker Red) confirmed a statistically significant reduction of both after mRNA treatment (Figures $4 \mathrm{~F}$ and $4 \mathrm{G}$ ). To the best of our knowledge, this is the first time exogenous mRNA has been used to rescue the protein insufficiency and pathogenic phenotype caused by NPC1 disease. Nevertheless, further investigation is required to advance this work towards clinical application. Of significant importance to conducting an in vivo proof-of-concept study is the need for a non-viral delivery system capable of safely and effectively transporting NPC1 mRNA to the relevant affected tissues, especially the brain and liver.

\section{Author contributions}

D.F., C.C.-J., F.C., Y.H.H., and A.I.B. designed the research. D.F. conducted the experiments. F.C. supervised the project. D.F. wrote the manuscript with input from all other authors.

\section{Conflicts of interest}

A provisional patent application has been filed by the University of Melbourne in relation to this work. D.F. and F.C. are directors of and equity holders in Messenger Bio Pty Ltd. A.I.B. is a shareholder in Alterity Ltd., Cogstate Ltd., Brighton Biotech LLC, Grunbiotics Pty Ltd., Eucalyptus Pty Ltd., and Mesoblast Ltd. He is a paid consultant for, and has a profit share interest in, Collaborative Medicinal Development Pty Ltd.

\section{Acknowledgements}

This research was funded by the National Health and Medical Research Council (NHMRC) (GNT1149990, F.C.). Y.H.H. and A.I.B. acknowledge grant funding from the Australian NPC Disease Foundation. F.C. acknowledges the award of an NHMRC Senior Principal Research Fellowship (GNT1135806). C.C.-J. acknowledges support from the Friedreich's Ataxia Research Alliance and fara Australia. D.F. acknowledges the award of a Westpac Future Leader's Scholarship from the Westpac Foundation. We acknowledge the Biological Optical Microscopy Platform (BOMP) at the University of Melbourne for access to the PerkinElmer Operetta CLS High Content Imaging System.

\section{References}

1 Vanier, M. T. Niemann-Pick disease type C. Orphanet Journal of Rare Diseases 5, 16, doi:10.1186/1750-1172-5-16 (2010).

2 Wassif, C. A. et al. High incidence of unrecognized visceral/neurological late-onset Niemann-Pick disease, type C1, predicted by analysis of massively parallel sequencing data sets. Genetics in Medicine 18, 41-48, doi:10.1038/gim.2015.25 (2016).

3 Subramanian, K. \& Balch, W. E. NPC1/NPC2 function as a tag team duo to mobilize cholesterol. Proceedings of the National Academy of Sciences 105, 15223, doi:10.1073/pnas.0808256105 (2008).

$4 \quad$ Höglinger, D. et al. NPC1 regulates ER contacts with endocytic organelles to mediate cholesterol egress. Nature Communications 10, 4276, doi:10.1038/s41467-019-12152-2 (2019).

$5 \quad$ Sleat, D. E. et al. Genetic evidence for nonredundant functional cooperativity between NPC1 and NPC2 in lipid transport. Proceedings of the National Academy of Sciences of the United States of America 101, 5886, doi:10.1073/pnas.0308456101 (2004).

6 Kwon, H. J. et al. Structure of N-Terminal Domain of NPC1 Reveals Distinct Subdomains for Binding and Transfer of Cholesterol. Cell 137, 1213-1224, doi:https://doi.org/10.1016/i.cell.2009.03.049 (2009).

7 Patterson, M. C. et al. Recommendations for the diagnosis and management of Niemann-Pick disease type C: An update. Molecular Genetics and Metabolism 106, 330-344, doi:https://doi.org/10.1016/i.ymgme.2012.03.012 (2012). Yanjanin, N. M. et al. Linear clinical progression, independent of age of onset, in Niemann-Pick disease, type C. American Journal of Medical Genetics Part B: Neuropsychiatric Genetics 153B, 132-140, doi:https://doi.org/10.1002/ajmg.b.30969 (2010). 
bioRxiv preprint doi: https://doi.org/10.1101/2022.02.21.479058; this version posted February 24, 2022. The copyright holder for this

preprint (which was not certified by peer review) is the author/funder, who has granted bioRxiv a license to display the preprint in perpetuity. It is made available under aCC-BY-ND 4.0 International license.

Hammond, N., Munkacsi, A. B. \& Sturley, S. L. The complexity of a monogenic neurodegenerative disease: More than two decades of therapeutic driven research into Niemann-Pick type $\mathrm{C}$ disease. Biochimica et Biophysica Acta (BBA) - Molecular and Cell Biology of Lipids 1864, 1109-1123, doi:https://doi.org/10.1016/j.bbalip.2019.04.002 (2019). Kirkegaard, T. et al. Heat shock protein-based therapy as a potential candidate for treating the sphingolipidoses. Science Translational Medicine 8, 355ra118, doi:10.1126/scitranslmed.aad9823 (2016). Patterson, M. C. et al. Treatment outcomes following continuous miglustat therapy in patients with Niemann-Pick disease Type C: a final report of the NPC Registry. Orphanet Journal of Rare Diseases 15, 1-10 (2020). Solomon, B. I. et al. Association of Miglustat With Swallowing Outcomes in Niemann-Pick Disease, Type C1. JAMA Neurology 77, 1564-1568, doi:10.1001/jamaneurol.2020.3241 (2020). Liu, B. et al. Reversal of defective lysosomal transport in NPC disease ameliorates liver dysfunction and neurodegeneration in the npc1-/- mouse. Proceedings of the National Academy of Sciences 106, 2377, doi:10.1073/pnas.0810895106 (2009). Hastings, C. et al. Expanded access with intravenous hydroxypropyl- $\beta$-cyclodextrin to treat children and young adults with Niemann-Pick disease type C1: a case report analysis. Orphanet Journal of Rare Diseases 14, 228, doi:10.1186/s13023-019-1207-1 (2019). Nielsen, G. K. et al. Protein Replacement Therapy Partially Corrects the Cholesterol-Storage Phenotype in a Mouse Model of Niemann-Pick Type C2 Disease. PLOS ONE 6, e27287, doi:10.1371/journal.pone.0027287 (2011). Chandler, R. J. et al. Systemic AAV9 gene therapy improves the lifespan of mice
C1. Human Molecular Genetics 26, 52-64, doi:10.1093/hmg/ddw367 (2017). C1. Human Molecular Genetics 26, 52-64, doi:10.1093/hmg/ddw367 (2017).
Hughes, M. P. et al. AAV9 intracerebroventricular gene therapy improves life in a mouse model of Niemann-Pick type C1 disease. Human Molecular Genetics 27, 3079-3098, doi:10.1093/hmg/ddy212 (2018). Xie, C., Gong, X.-M., Luo, J., Li, B.-L. \& Song, B.-L. AAV9-NPC1 significantly ameliorates Purkinje cell death and behavioral abnormalities in mouse NPC disease. Journal of Lipid Research 58, 512-518, doi:https://doi.org/10.1194/jlr.M071274 (2017). Therapy for Krabbe Disease. Molecular Therapy 29, 691-701, doi:https://doi.org/10.1016/i.ymthe.2020.12.031 (2021). Gene Transfer. Molecular Therapy 28, 723-746, doi:https://doi.org/10.1016/i.ymthe.2019.12.010 (2020). Kole, R., Krainer, A. R. \& Altman, S. RNA therapeutics: beyond RNA interference and antisense oligonucleotides. Nature Reviews Drug Discovery 11, 125-140, doi:10.1038/nrd3625 (2012). Sahin, U., Karikó, K. \& Türeci, Ö. mRNA-based therapeutics - developing a new class of drugs. Nature Reviews Drug Discovery 13, 759-780, doi:10.1038/nrd4278 (2014). Weissman, D. mRNA transcript therapy. Expert Review of Vaccines 14, 265-281, doi:10.1586/14760584.2015.973859 (2015). Robinson, E. et al. Lipid Nanoparticle-Delivered Chemically Modified mRNA Restores Chloride Secretion in Cystic Fibrosis. Molecular Therapy 26, 2034-2046, doi:https://doi.org/10.1016/i.ymthe.2018.05.014 (2018). Karadagi, A. et al. Systemic modified messenger RNA for replacement therapy in alpha 1-antitrypsin deficiency. Scientific Reports 10, 7052, doi:10.1038/s41598-020-64017-0 (2020). An, D. et al. Systemic Messenger RNA Therapy as a Treatment for Methylmalonic Acidemia. Cell Reports 21, 35483558, doi:https://doi.org/10.1016/j.celrep.2017.11.081 (2017). Ramaswamy, S. et al. Systemic delivery of factor IX messenger RNA for protein replacement therapy. Proceedings of the National Academy of Sciences 114, E1941, doi:10.1073/pnas.1619653114 (2017). Strenkowska, M. et al. Cap analogs modified with 1,2-dithiodiphosphate moiety protect mRNA from decapping and enhance its translational potential. Nucleic Acids Research 44, 9578-9590, doi:10.1093/nar/gkw896 (2016). Sample, P. J. et al. Human 5' UTR design and variant effect prediction from a massively parallel translation assay. Nature Biotechnology 37, 803-809, doi:10.1038/s41587-019-0164-5 (2019). Floor, S. N. \& Doudna, J. A. Tunable protein synthesis by transcript isoforms in human cells. eLife 5, e10921, doi:10.7554/eLife.10921 (2016). Biology 15, 756-762, doi:10.1080/15476286.2018.1450054 (2018). Holtkamp, S. et al. Modification of antigen-encoding RNA increases stability, translational efficacy, and T-cell stimulatory capacity of dendritic cells. Blood 108, 4009-4017, doi:10.1182/blood-2006-04-015024 (2006). Mauger, D. M et al. mRNA structure regulates protein expression through changes in functional half-life. Proceedings of the National Academy of Sciences 116, 24075, doi:10.1073/pnas.1908052116 (2019).

34 Thess, A. et al. Sequence-engineered mRNA Without Chemical Nucleoside Modifications Enables an Effective Protein Therapy in Large Animals. Molecular Therapy 23, 1456-1464, doi:10.1038/mt.2015.103 (2015). Svitkin, Y. V. et al. N1-methyl-pseudouridine in mRNA enhances translation through elF2a-dependent and independent mechanisms by increasing ribosome density. Nucleic Acids Research 45, 6023-6036, doi:10.1093/nar/gkx135 (2017).

Karikó, K., Buckstein, M., Ni, H. \& Weissman, D. Suppression of RNA Recognition by Toll-like Receptors: The Impact of Nucleoside Modification and the Evolutionary Origin of RNA. Immunity 23, 165-175, doi:https://doi.org/10.1016/i.immuni.2005.06.008 (2005). Karikó, K. et al. Incorporation of Pseudouridine Into mRNA Yields Superior Nonimmunogenic Vector With Increased Translational Capacity and Biological Stability. Molecular Therapy 16, 1833-1840, doi:https://doi.org/10.1038/mt.2008.200 (2008). $3^{*}$. Journal of Biological Chemistry 279, 12542-12550, doi:https://doi.org/10.1074/jbc.M310175200 (2004). doi:https://doi.org/10.15252/embr.201948220 (2019). 
bioRxiv preprint doi: https://doi.org/10.1101/2022.02.21.479058; this version posted February 24, 2022. The copyright holder for this

preprint (which was not certified by peer review) is the author/funder, who has granted bioRxiv a license to display the preprint in perpetuity. It is made available under aCC-BY-ND 4.0 International license.

Wang, X., Kiledjian, M., Weiss, I. M. \& Liebhaber, S. A. Detection and characterization of a 3' untranslated region ribonucleoprotein complex associated with human alpha-globin mRNA stability. Molecular and Cellular Biology 15, 1769, doi:10.1128/MCB.15.3.1769 (1995).

Baiersdörfer, M. et al. A Facile Method for the Removal of dsRNA Contaminant from In Vitro-Transcribed mRNA. Molecular Therapy - Nucleic Acids 15, 26-35, doi:https://doi.org/10.1016/i.omtn.2019.02.018 (2019). Lorenz, R. et al. ViennaRNA Package 2.0. Algorithms for Molecular Biology 6, 26, doi:10.1186/1748-7188-6-26 (2011).

Mathews, D. H. et al. Incorporating chemical modification constraints into a dynamic programming algorithm for prediction of RNA secondary structure. Proceedings of the National Academy of Sciences of the United States of America 101, 7287, doi:10.1073/pnas.0401799101 (2004).

Silvers, R., Keller, H., Schwalbe, H. \& Hengesbach, M. Differential Scanning Fluorimetry for Monitoring RNA Stability. ChemBioChem 16, 1109-1114, doi:https://doi.org/10.1002/cbic.201500046 (2015).

Mauro, V. P. \& Chappell, S. A. A critical analysis of codon optimization in human therapeutics. Trends in Molecular Medicine 20, 604-613, doi:https://doi.org/10.1016/i.molmed.2014.09.003 (2014).

Villalobos, A., Ness, J. E., Gustafsson, C., Minshull, J. \& Govindarajan, S. Gene Designer: a synthetic biology tool for constructing artificial DNA segments. BMC Bioinformatics 7, 285, doi:10.1186/1471-2105-7-285 (2006).

Deng, T. Bacterial expression and purification of biologically active mouse c-Fos proteins by selective codon optimization. FEBS Letters 409, 269-272, doi:https://doi.org/10.1016/S0014-5793(97)00522-X (1997). the Codon Usage Frequencies of the Target Gene with those of the Expression Host. PLOS ONE 3, e2189, doi:10.1371/journal.pone.0002189 (2008).

Wu, G., Bashir-Bello, N. \& Freeland, S. J. The Synthetic Gene Designer: A flexible web platform to explore sequence manipulation for heterologous expression. Protein Expression and Purification 47, 441-445, doi:https://doi.org/10.1016/i.pep.2005.10.020 (2006).

Qian, W., Yang, J.-R., Pearson, N. M., Maclean, C. \& Zhang, J. Balanced Codon Usage Optimizes Eukaryotic Translational Efficiency. PLOS Genetics 8, e1002603, doi:10.1371/journal.pgen.1002603 (2012).

Raab, D., Graf, M., Notka, F., Schödl, T. \& Wagner, R. The GeneOptimizer Algorithm: using a sliding window approach to cope with the vast sequence space in multiparameter DNA sequence optimization. Systems and Synthetic Biology 4, 215-225, doi:10.1007/s11693-010-9062-3 (2010).

Vaidyanathan, S. et al. Uridine Depletion and Chemical Modification Increase Cas9 mRNA Activity and Reduce Immunogenicity without HPLC Purification. Molecular Therapy - Nucleic Acids 12, 530-542, doi:https://doi.org/10.1016/i.omtn.2018.06.010 (2018).

Andries, O. et al. N1-methylpseudouridine-incorporated mRNA outperforms pseudouridine-incorporated mRNA by providing enhanced protein expression and reduced immunogenicity in mammalian cell lines and mice. Journal of Controlled Release 217, 337-344, doi:https://doi.org/10.1016/i.jconrel.2015.08.051 (2015).

Li, B., Luo, X. \& Dong, Y. Effects of Chemically Modified Messenger RNA on Protein Expression. Bioconjugate Chemistry 27, 849-853, doi:10.1021/acs.bioconjchem.6b00090 (2016).

Pentchev, P. G. et al. The cholesterol storage disorder of the mutant BALB/c mouse. A primary genetic lesion closely linked to defective esterification of exogenously derived cholesterol and its relationship to human type $\mathrm{C}$ Niemann-Pick disease. Journal of Biological Chemistry 261, 2772-2777, doi:https://doi.org/10.1016/S00219258(17)35852-0 (1986).

Park, W. D. et al. Identification of 58 novel mutations in Niemann-Pick disease type C: Correlation with biochemical phenotype and importance of PTC1-like domains in NPC1. Human Mutation 22, 313-325, doi:https://doi.org/10.1002/humu.10255 (2003).

Norman, A. W., Demel, R. A., de Kruyff, B. \& van Deenen, L. L. M. Studies on the Biological Properties of Polyene Antibiotics: EVIDENCE FOR THE DIRECT INTERACTION OF FILIPIN WITH CHOLESTEROL. Journal of Biological Chemistry 247, 1918-1929, doi:https://doi.org/10.1016/S0021-9258(19)45558-0 (1972).

Jiang, L. et al. Systemic messenger RNA as an etiological treatment for acute intermittent porphyria. Nature Medicine 24, 1899-1909, doi:10.1038/s41591-018-0199-z (2018).

Prieve, M. G. et al. Targeted mRNA Therapy for Ornithine Transcarbamylase Deficiency. Molecular Therapy 26, 801813, doi:https://doi.org/10.1016/i.ymthe.2017.12.024 (2018).

Sago, C. D. et al. High-throughput in vivo screen of functional mRNA delivery identifies nanoparticles for endothelia cell gene editing. Proceedings of the National Academy of Sciences 115, E9944, doi:10.1073/pnas.1811276115 (2018).

Truong, B. et al. Lipid nanoparticle-targeted mRNA therapy as a treatment for the inherited metabolic liver disorder arginase deficiency. Proceedings of the National Academy of Sciences 116, 21150, doi:10.1073/pnas.1906182116 (2019).

Cao, J. et al. mRNA Therapy Improves Metabolic and Behavioral Abnormalities in a Murine Model of Citrin Deficiency. Molecular Therapy 27, 1242-1251, doi:https://doi.org/10.1016/j.ymthe.2019.04.017 (2019).

disease. Nature Communications 12, 3090, doi:10.1038/s41467-021-23318-2 (2021). Galactose Sensitivity in a Mouse Model of Classic Galactosemia. Molecular Therapy 28, 304-312, doi:https://doi.org/10.1016/i.ymthe.2019.09.018 (2020).

Kudla, G., Lipinski, L., Caffin, F., Helwak, A. \& Zylicz, M. High Guanine and Cytosine Content Increases mRNA Levels in Mammalian Cells. PLOS Biology 4, e180, doi:10.1371/journal.pbio.0040180 (2006).

Li, X., Quon, G., Lipshitz, H. D. \& Morris, Q. Predicting in vivo binding sites of RNA-binding proteins using mRNA secondary structure. Rna 16, 1096-1107, doi:10.1261/rna.2017210 (2010).

Jungfleisch, J. et al. A novel translational control mechanism involving RNA structures within coding sequences. Genome Res 27, 95-106, doi:10.1101/gr.209015.116 (2017).

Anderson, B. R. et al. Nucleoside modifications in RNA limit activation of 2'-5'-oligoadenylate synthetase and increase resistance to cleavage by RNase L. Nucleic Acids Research 39, 9329-9338, doi:10.1093/nar/gkr586 (2011). 
bioRxiv preprint doi: https://doi.org/10.1101/2022.02.21.479058; this version posted February 24, 2022. The copyright holder for this

preprint (which was not certified by peer review) is the author/funder, who has granted bioRxiv a license to display the preprint in perpetuity. It is made available under aCC-BY-ND 4.0 International license.

Bounedjah, O. et al. Free mRNA in excess upon polysome dissociation is a scaffold for protein multimerization to form stress granules. Nucleic Acids Research 42, 8678-8691, doi:10.1093/nar/gku582 (2014).

70 Shack, S., Gorospe, M., Fawcett, T. W., Hudgins, W. R. \& Holbrook, N. J. Activation of the cholesterol pathway and Ras maturation in response to stress. Oncogene 18, 6021-6028, doi:10.1038/sj.onc.1203002 (1999).

71 Gesquière, L., Loreau, N., Minnich, A., Davignon, J. \& Blache, D. Oxidative stress leads to cholesterol accumulation in vascular smooth muscle cells. Free Radical Biology and Medicine 27, 134-145,

doi:https://doi.org/10.1016/S0891-5849(99)00055-6 (1999). 